\title{
اثر عوامل الضغط النفسي والاجتماعي على سلوك إدمان المفدرات
}

م.م علي كاظم عجة ألثمري

جامعة واسط / كلية التربية

تثير الإحصائيات الصادرة عن البرنامج العالمي لمكافحة المخدرات (UNDCP)، والمكتب العربي

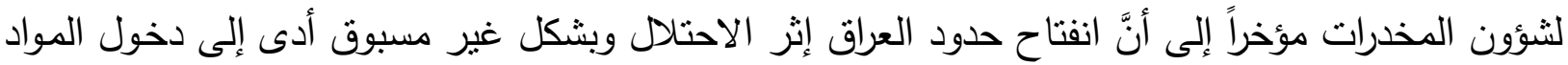

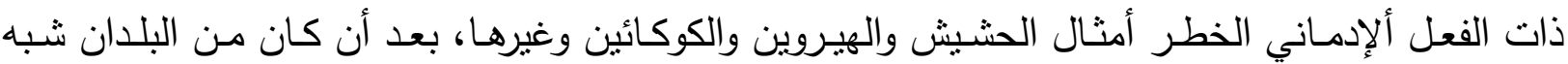

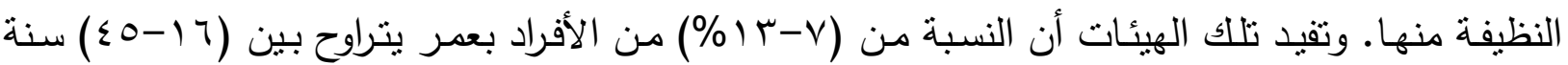

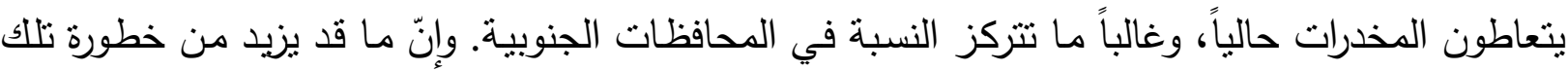

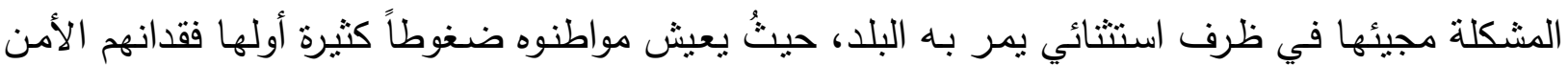
نتيجة حالة الفوضى والتدهور المانلة في الثارع العراقي ـ ما قد يدفع البعض منهم لتعاطي تلاك المواد بهدف التخفيف من الآثار النفسية الصدمية الناجمة عن تلاك الضغوط. لذا جاء البحث الحالي بهدف التعرف فيما

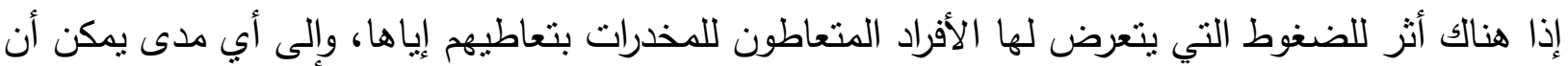
تتكل تلك الضغوط عوامل سبيية أصلية في إحداث سلوك التعاطي للمواد المخدرة أو مديمة له. تنَّ اختيار ( . (1) فرد من متعاطي المواد المخدرة المراجعين والراقدين في الثتب النفسية لمستشفيات الزهراء والكرامة والطواريء في الكوت مثلوا المجموعة (السريرية)، كما تم اختيار ( . ( ) فرد من غير المتعاطين من المجتمع

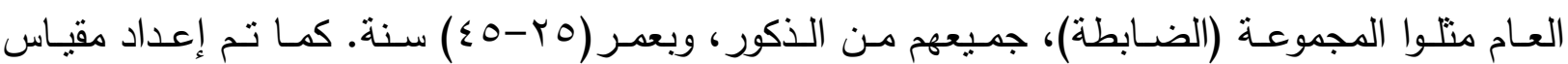
للضغوط النفسية والاجتماعية للإدمان، بلغ (Yo) فقرة و استخرج الصدق للهُ بمؤشرين:ظاهري وبناء، كذللك

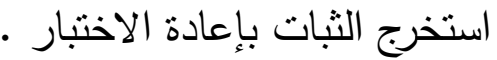
النتائج : ظهرَّ أنَّ الأفراد متعاطي المخدرات أكثر تعرضاً للضغوط النفسية والاجتماعية من غير المتعاطين،

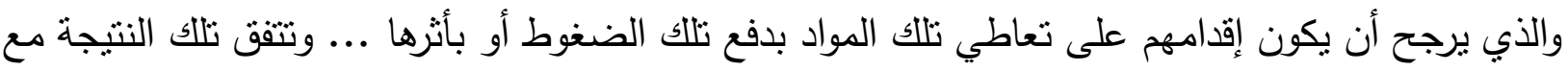

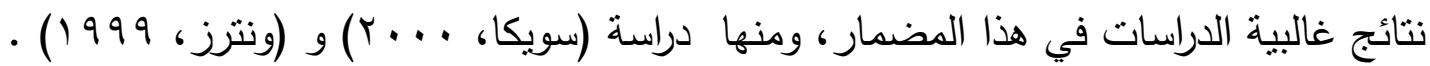

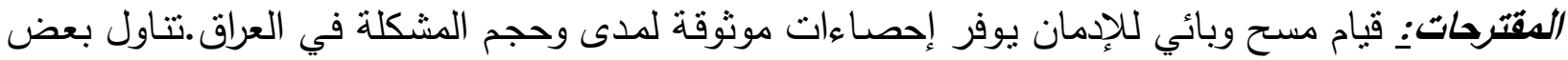
المتغيرات النفسية والاجتماعيـة ذات العلاقـة بظـاهرة تعـاطي المخدرات منها (الحرمـان الاجتمـاعي،والأمن

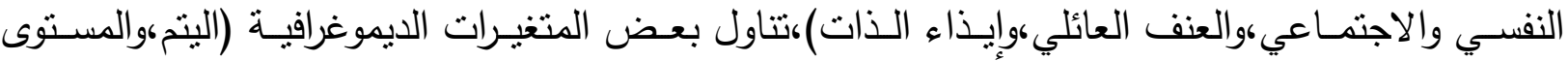

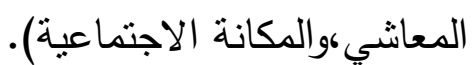

التوصيات: ندعو إلى تأسيس (لجنة وطنية ) يمتزج فيها عمل الجميع من مؤسسات أمنية وصحية وقانونية

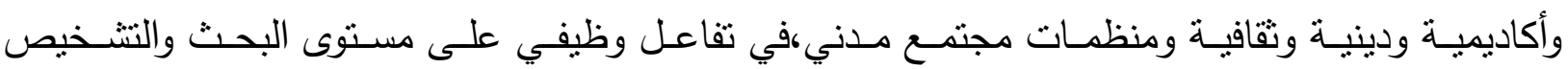
والتخطيط والتنفيذ، كلٌ باختصاصـه يعمل إزاء الظاهرة، وتقتح مراكز لها في جميع المحافظات ولاسيما الجنوبية منها. تكثيف جهود وزارة الداخلية ووزارة الأمن الوطني لمراقبة الحدود. 


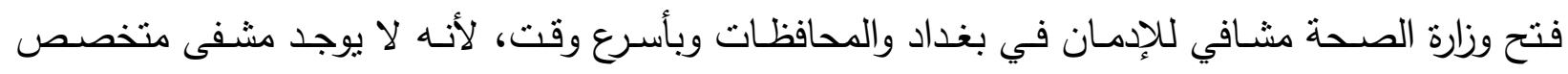

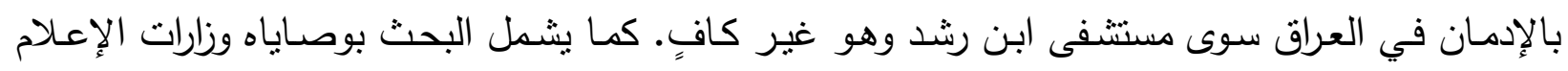

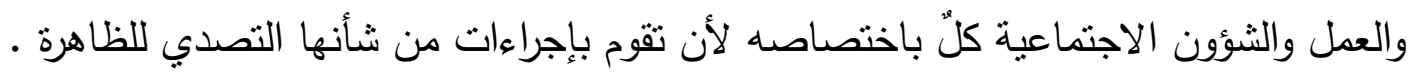

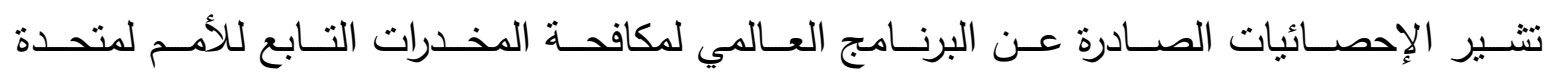

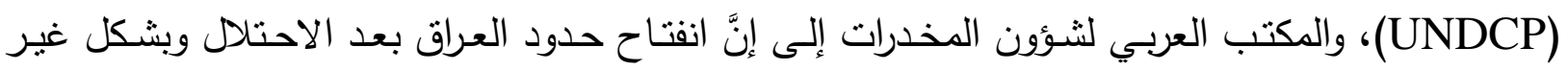

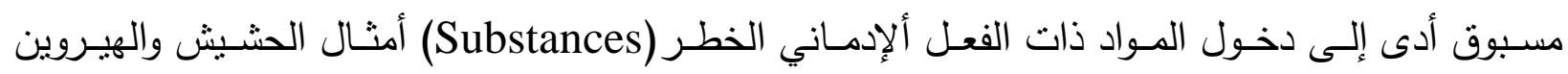

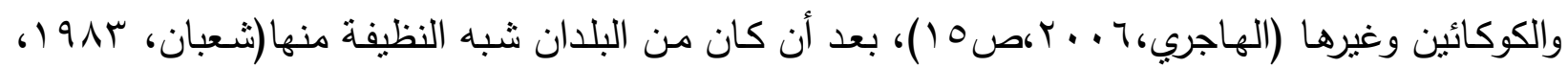

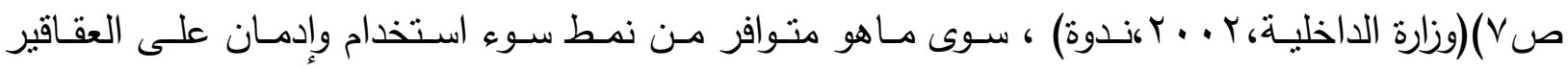

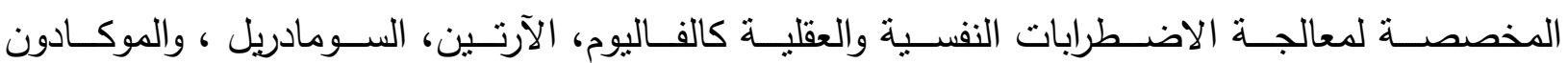

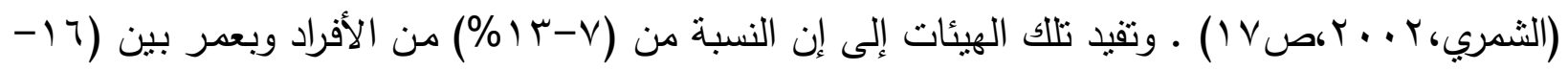

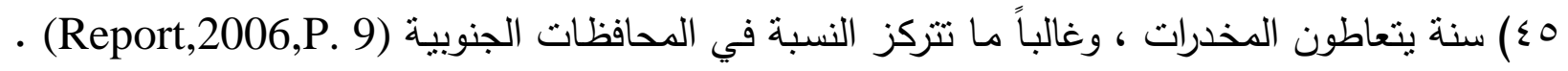

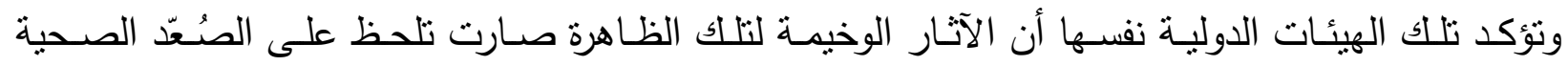
والاجتماعية والاقتصادية والقانونية والسياسية في البلد لتفاقم الساحة العراقية المبتلية مؤخراً بأنشطة جريمة الفية

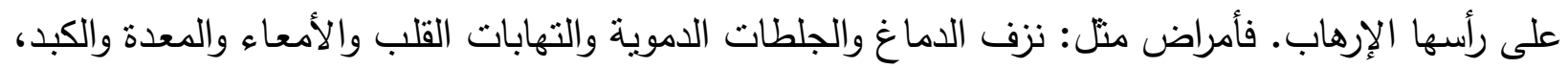

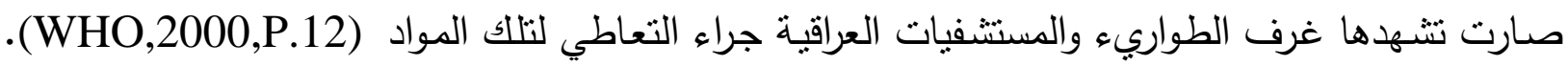

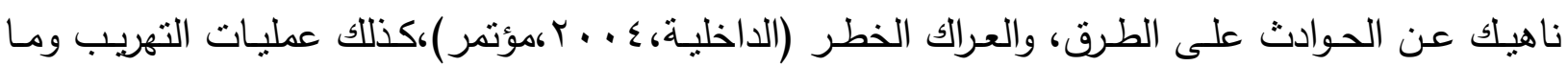

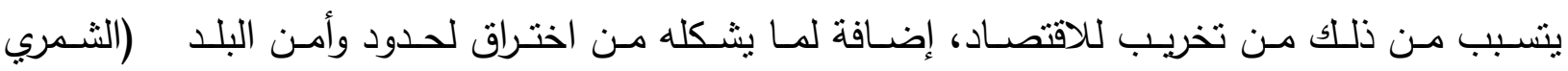

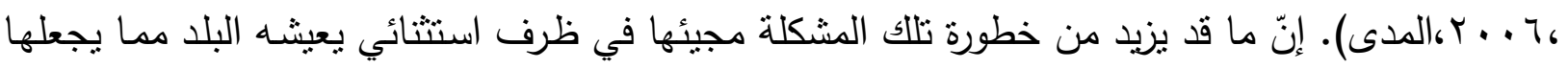

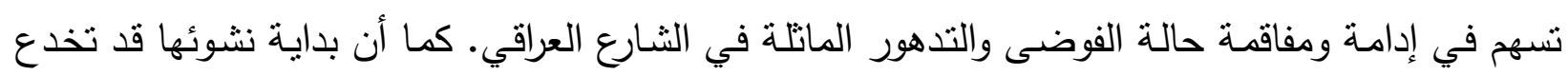
الكثيرين بسبب عدم إدراك طبيعتها القائمة على السريان البطيء ثم الظهور فجأة على جسد المجتمع نظراً

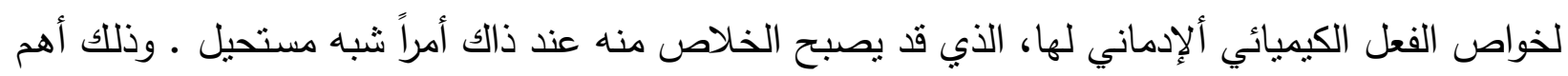

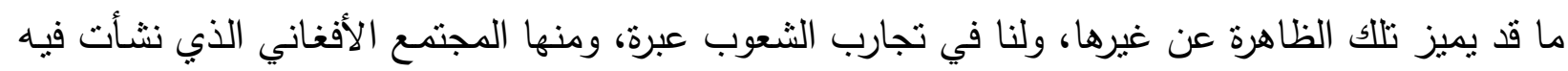

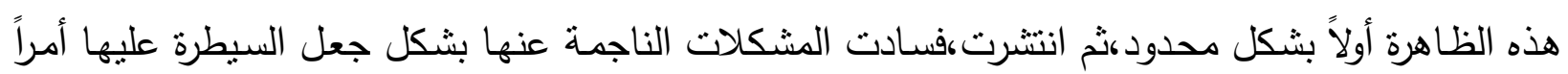
شبه مستحيل (UNDCP,2006,P.6). ومن جانب آخر فان إفادة خبراء منظمة الصحة العالمية العاملين

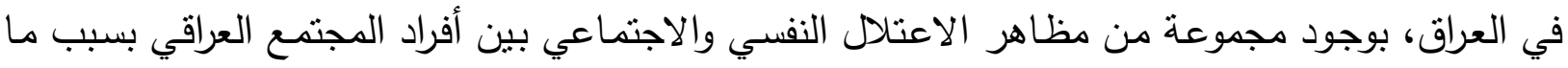

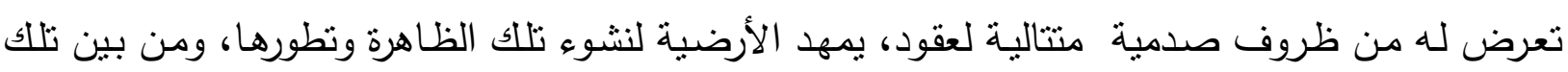

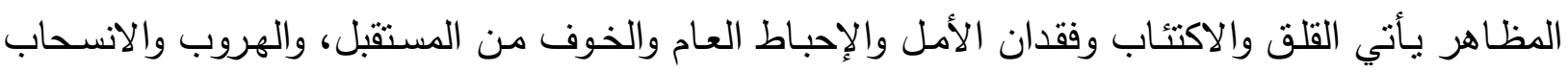

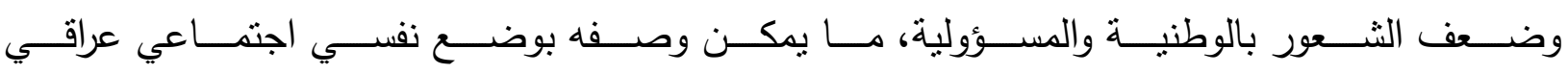
معتل (UNReport,2007,P.11) . وما يزيد من خطورة ذلك هو أرجحية نشوئها في صفوف المراهقين والثباب في ظل ما يعانونه من ضغط المعيشة وتفشي البطالة، أو مجالات التوظيف الخطرة، وهو ما تقيد التيد 
به بعض الجهات، وهي من العوامل الرئيسة في تسبيب سلوك إدمان المخدرات بحسب إنشارة الدراسات . (UNDCP,1997,P.11)

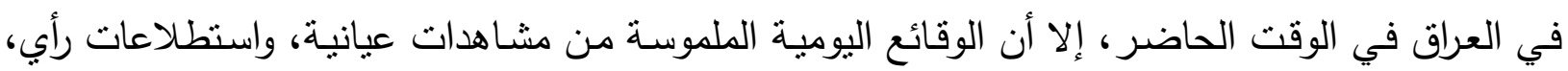

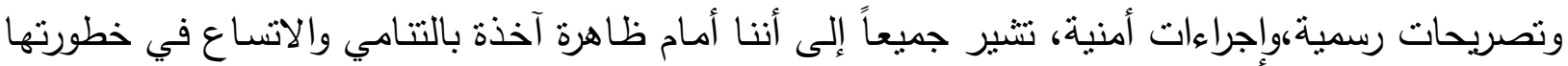

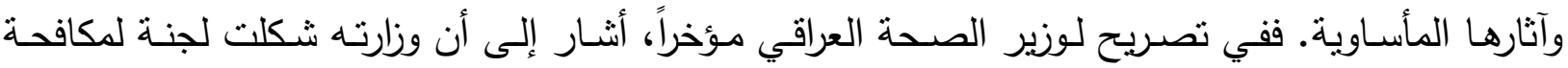

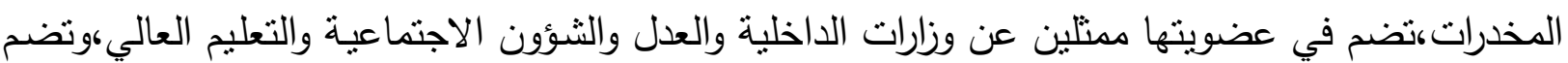
خبراء اختصاص لوضع الخطط الكفيلة بمكافحة تعاطي وبيع المخدرات بأنواعها المتعددة. وفي تصريحات

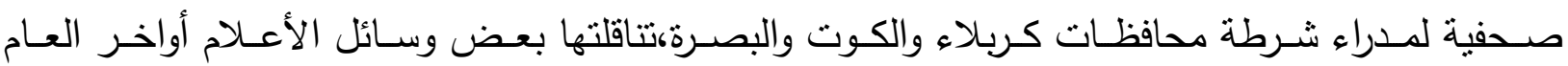

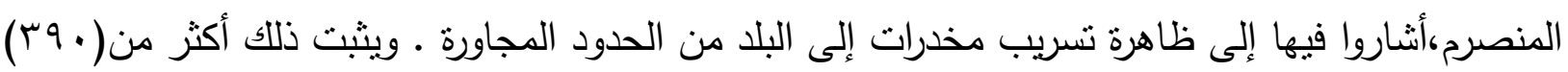
حالة ضبط لتلك المواد المخدرة من قبل مفارز الثرطة العراقية في تلك المحافظات. وفي استطلاعين للأي

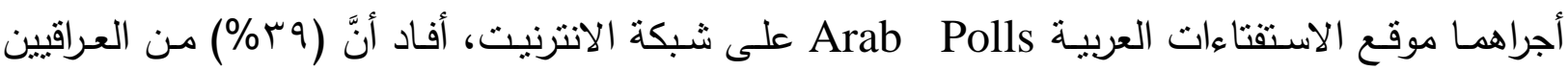

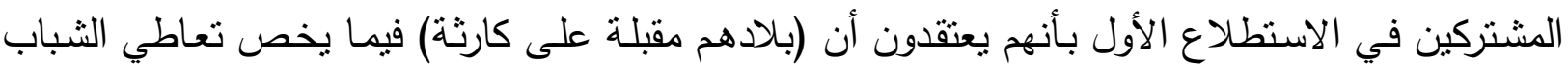

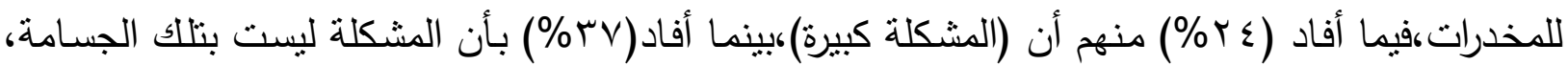

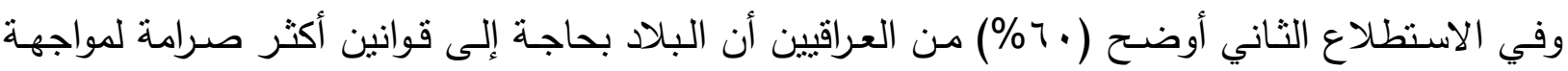

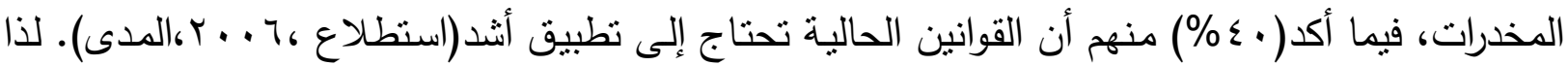

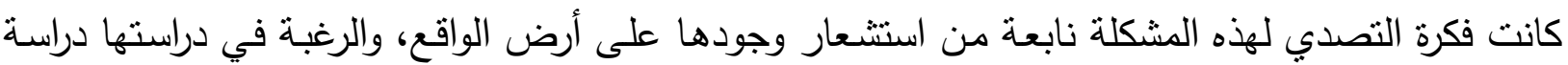

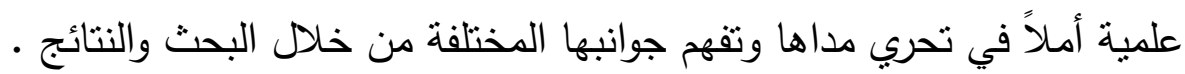
بناء على ما تقدم، يسعى الباحث للإجابة عن السؤال الآتي:هل للضغوط النفسية والاجتماعية التي

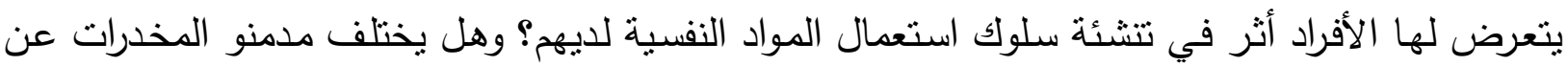

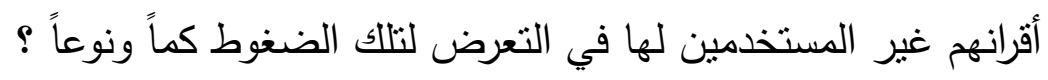
أهداف البحث : يهدف البحث إلى التعرف على ما إذا كانت هناك فروق بين المدمنين على الدخدرات وغيرالمدمنين في الضغوط النفسية والاجتماعية .

حدود البحث :يتحدد البحث الحالي بمتعاطي المخدرات من المرضى الراقدين والمراجعين للشعب النفسية

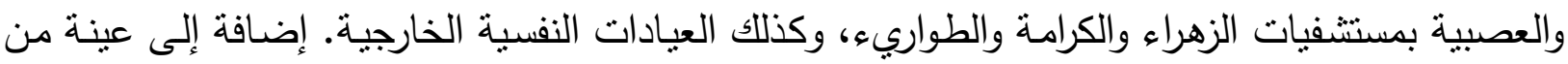

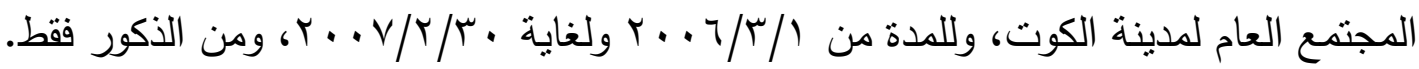
تصديد المصطحات

\section{أولاً- الضغوط النفسية والاجتماعية_ Psycho Social Pressure Factors}

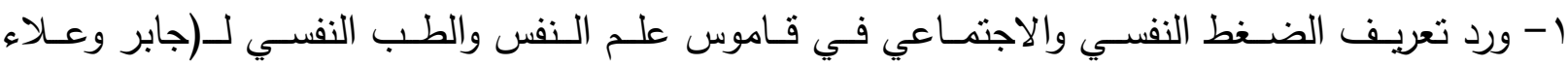

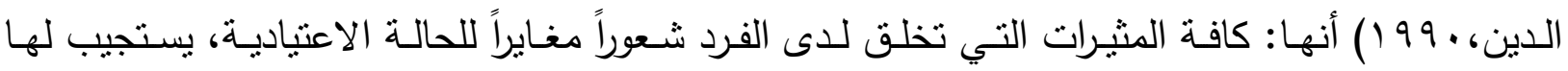

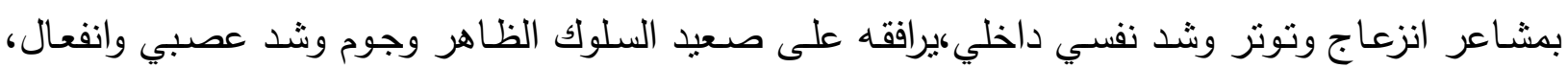


وبحسب شدة واستمرارية الضغوط تزداد حدة تلك العلامات والأعراض، حتى بمكن أن تصل إلى درجة قد

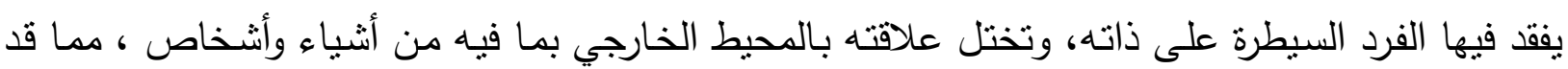
جابر يترتب عليه انحرافات في السلوك كأن يكون عدائياً أو سلبياً أو مدمناً

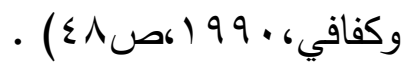

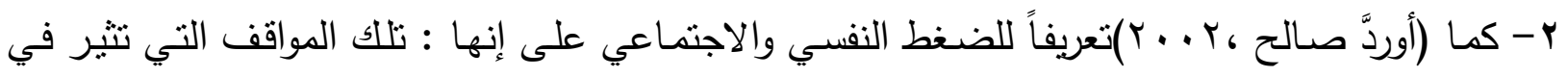

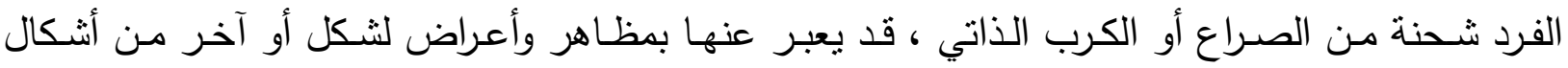

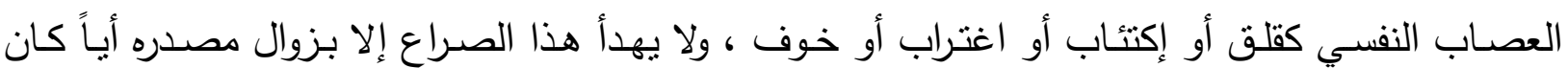

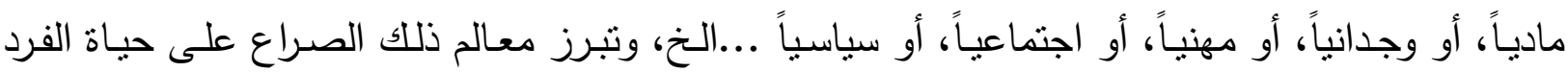

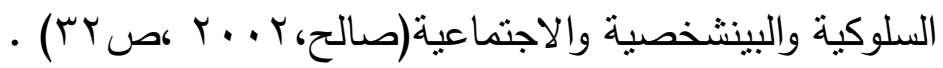

\section{ثُانياً - إدمان المخدرات}

1- ورد تعريف الإدمان على المواد النفسية في المراجعة العاشرة من التصنيف العالمي للاضطرابات النفسية

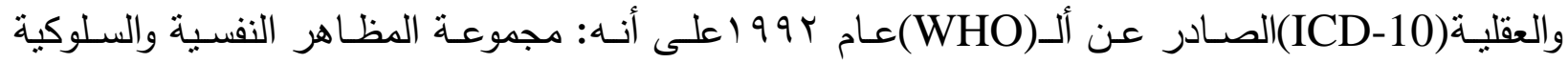

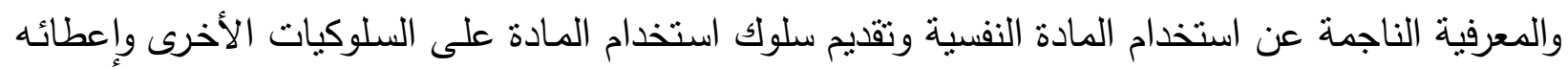

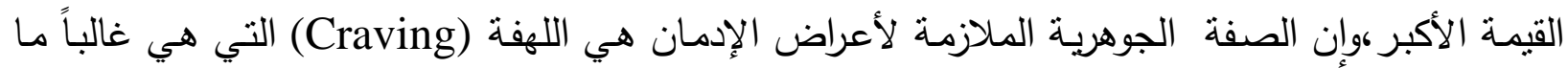
تكون قوية ولا تقاوم (ICD-10,1992,P. 75) •

Y- ورد تعريف اضـراب الاعتمـاد على المـواد النفسية في دليل نتـخيص الأمـراض النفسية والعقليـة الأمريكي(DSM-IV-R) في طبعته الرابعة المنقحة لعام2000 على أنـهُ : مجموعة الأعراض السلوكية والفسلجية والمعرفية التي تثير إلى إن الفرد مستمر في استخدام مادة ما، على الرغم من المشكلات الناجمة الإلها

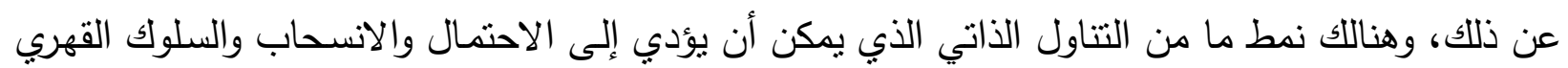
لتتاول المادة (DSM-IV-TR 2000,P.192) .وقد نبنى الباحث نظرياً تعريف الطبعة الرابعة المنقحة

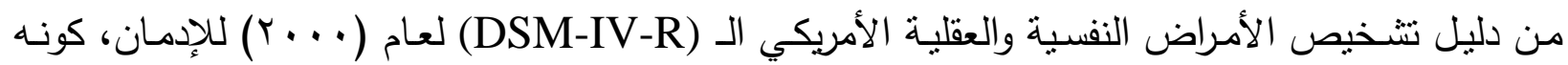

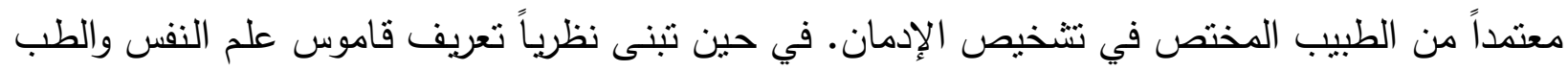

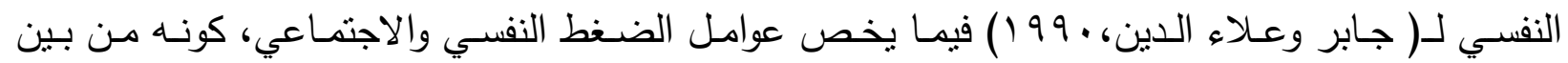
المصادر المستخدمة في بناء مقياس الضغط النفسي والاجتماعي المعتمد في البحث .كما تم تعريف إدمان

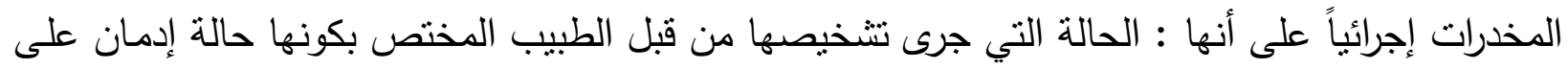
المخدرات على وفق لمعايير التتخيص المعتمدة بهذا الخصوص .وتم تعريف الضغوط النفسية والاجتماعية إجرائياً على إنها :الدرجة التي يحصل عليها المفحوص على مقياس الضغط النفسي والاجتماعي المعتمد في البحث. 
أثتارت مشكلة إدمان المخدرات اهتمام المختصين في فروع المعرفة المختلفة كعلم النفس والاجتماع والطب. وكل تلك العلوم ينظر إلى الظاهرة من زاويته الخاصـة ، ومـا زال النقاش محتدماً حول الأسباب الكامنة وراء تلك المشكلة . وجل

أ- العوامل الإحيائية : تشير بعض الدراسـات إلى أن هناك استعدادا لإدمان المخدرات أساسـه وراثي، من بين تلك الدراسـات واحدة تابعت التاريخ الطبيعي للعائلـة لتحري دور المؤثرات الوراثيـة في سلوك استخدام العقار بدراسـة نسبة حدوث إدمان العقاقير في أُسّر المدمنين وَلوُحِظَ أنَّ نسبة تعـاطي العقاقير بين أبناء الأسر المدمنة يتراوح بين ثلاثة إلى سبعة عثر أمثال نسبة حدوث ذلك بين أبناء الأسر غير المدمنة، مع إن هنالك من يشير إلى إن هذا لا يعني بالضرورة انتقال الظاهرة بالمعنى الوراثي الطبيعي بقدر ما يعني

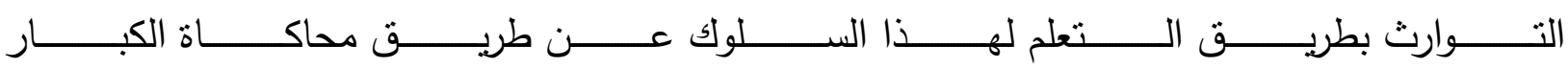
(Kandel,1978,P.41) خلية في الدماغ والجسم عموماً إلا وتتأثز بالمواد النفسية (NIAAA,2000,Special Report) • سوى أنَّ الجهاز العصبي المركزي يحتل الصدارة في هذا التأثثر لأنه المركز الرئيس الذي تعدل عليه تلك

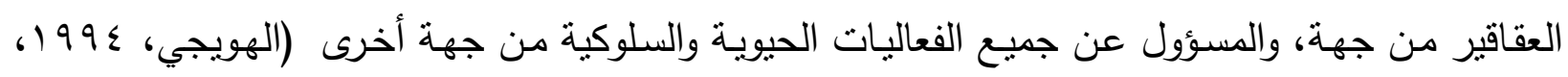
.

ب- العوامسل النفسية والاجتماعيـة : تشير المصـادر إلى العديد من العوامل النفسية والاجتماعيـة ، التي يمكن أن تُسهِ في إحداث ظاهرة إدمان المخدرات، ومن ذلك المحيط الأسري، فلعل من المُستَلَمات إن للأسرة تأثيراً كبيراً في الفرد إذ فيها ومنها يتعلم الإنسان المبادىء والقيم العامة التي تحكم السلوك والاتجاهات نحو مختلف جوانب الحياة التي يتعامل معها أو يمكن أن يتعرف إليها. وتدل الإحصائيات الحديثة على أنَّ كثيراً من المدمنين ينتمون إلى ما يزبد على ( • ع\%) من العائلات التي تقككت أواصرها وتلاشت الروابط الزوجية فيها، ويثير الخبراء النفسيون إلى أن البيت وما فيه من تفكلك للروابط العائلية، والمجتمع وما فيه من شرور

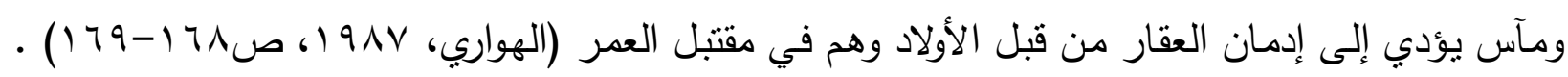
ويؤكد الباحثون دور العائلة المؤثر في المراهقة، وحاجة الفرد في مثل هذا العمر إلى رعايـة وتفهم اسري بدرجة أكثر من أيسة مرحلة أخرى، إذ إن الفرد هنا يسعى وبشكل دائب إلى توكيد ذاته ودوره في المحيط. وفي حالة حرمانه من ذللك فإنه قد يتمرد أو يكتئب أو يغتر ويحتمل في منل هذه الأحوال لجوؤه إلى استخدام المخدرات للتخفيف من تلك المعاناة، وباحتمال أكبر أيضاً أن يبحث له عن مجموعة رفاقية قد يجد فيها من الحب والاحتضـان مـا لم يجده في عائلته(مادلي، 9 (9 (، صب). وأشنارت الدراسـات كذلك إلى أن فاعلية العائلـة ودورهـا في تعلم هذا السلوك بوجـه خاص يشـاطرها فيسه عامل مهم آخر من خـارج المنزل متمثل بجماعة الأقران. ويعدهُ المختصون واحداُ من العوامل الأساسية في نشأة وتطور الظاهرة ، ولعل تضمينه كمجال في غالبية المقاييس المختصة بدراسة الظاهرة شاهد على ذلك( Winters ,1999,P.112 ) . وتشير الدراسات إلى إنَّ هناك نمطاً من الثخصية يكون أكثر أرجحية لانخراطه في سلوك تعاطي المخدرات من أبرز سماته: الحساسية العالية تجاه الذات والآخرين، وسرعة التأثر الوجداني، والعجز عن مواجهة الضغوط 
الخارجية والاندفاعية والقلق وسرعة الانفعال والبحث عن الإثارة وقلة الاتزان الانفعالي والعدوان كملمح شائع

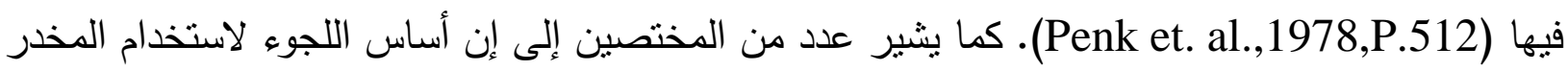

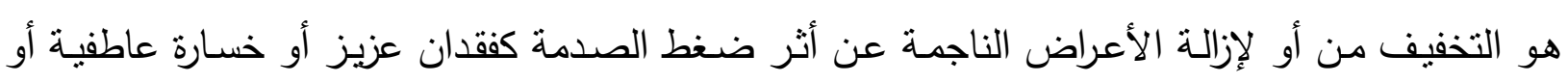

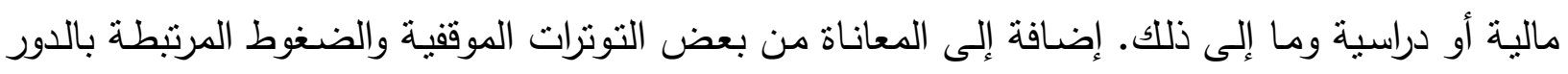

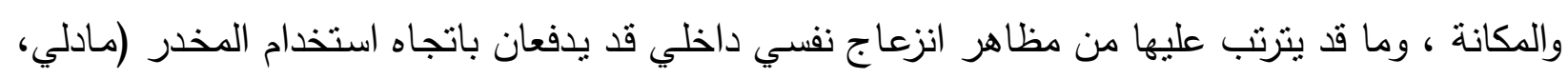

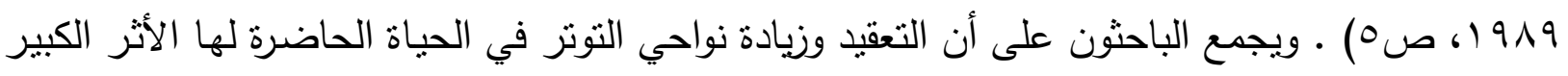

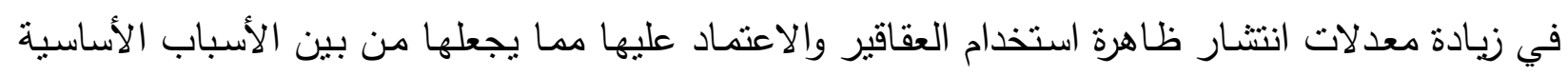

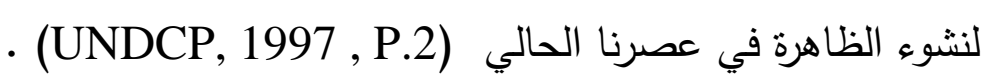
وهناك من الباحثين من يقسم الأسباب في هذا الإطار إلى عامة وخاصة. فالعامة هي التي يشترك فيها

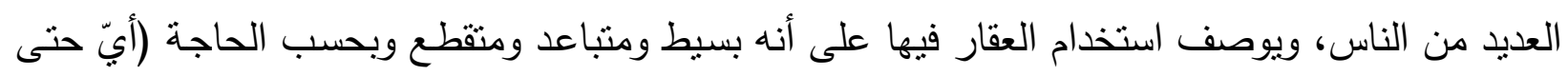

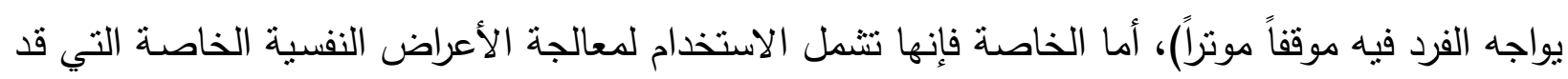

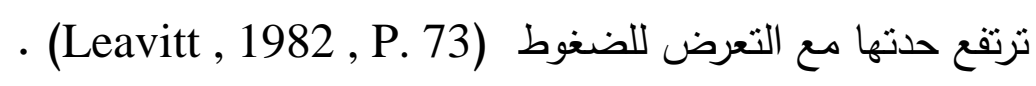
ومن الجدير بالذكر أن تأثثر تلك الأسباب في الظاهرة يتباين على وفق مراحل النمو النفسي للإنسان، بمعنى أن الأسباب النفسية في مرحلة النمو المبكر تختلف عنها في مرحلة المراهقة، وتلك الأخيرة بدورها

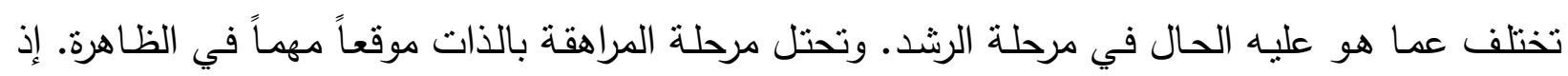

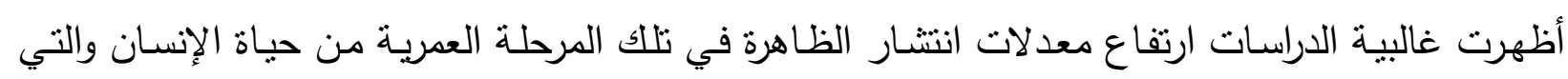
توصف بالنمو النفسي والجسدي الواضح ( Kandel ,1978 , P. 23). أما في نطاق مرحلة الرشد فغالباً

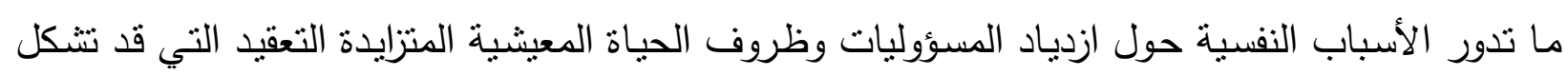
عاد

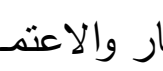
تخدام العق لانس

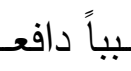

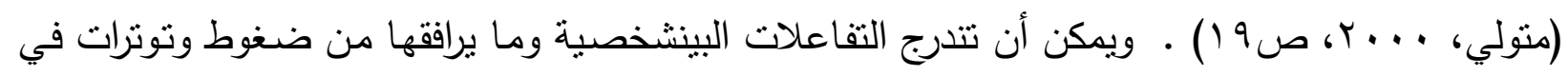

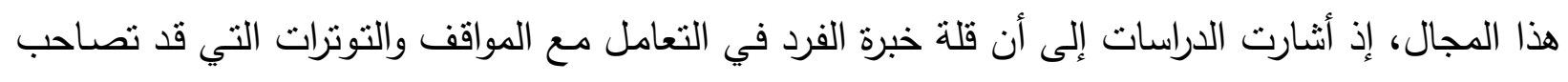

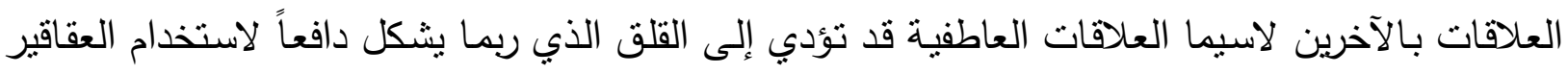

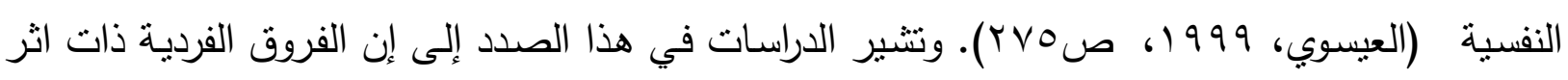

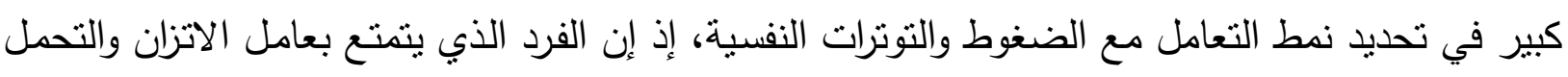

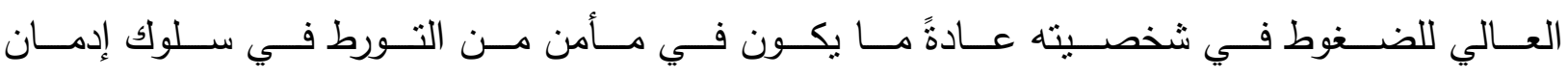

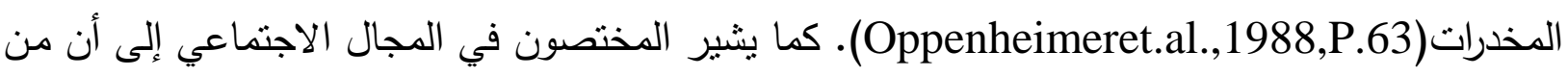

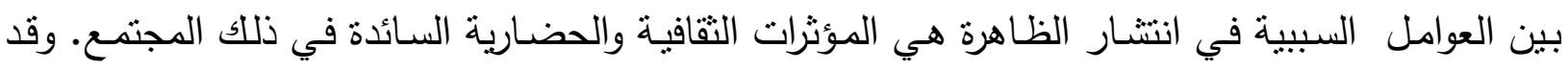

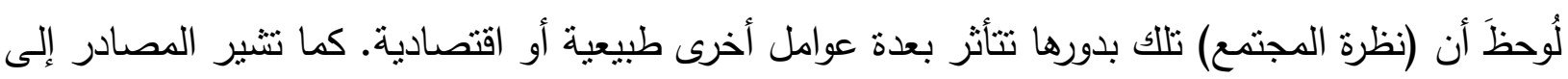

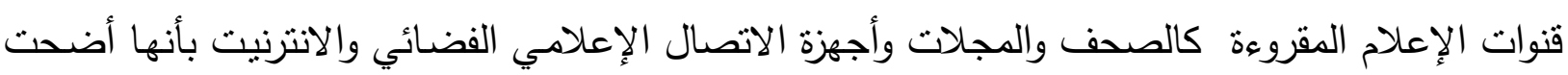

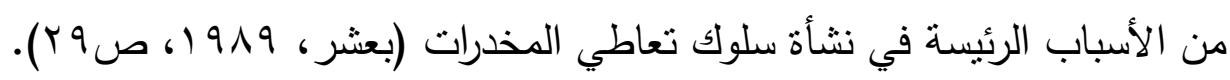


وخلاصـة مـا تقدم إنَّ كُلاً مِنَّ العوامل الأنفة الذكر لهـ دور في إحداث ظاهرة تعاطي المواد النفسية

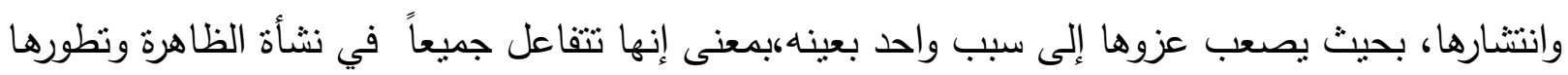
.(Maremmani,1999,P.5).(Kolybine\&Buddenberg,1998,P.2) r- الدراسات السابقة:

أ-دراسة بروك وآخرين (؟1911) : أجريت هذه الدراسة في المملكة المتحدة، وهدفت إلى التعرف على ( أثر ديناميات الثخصية في الطفولة والمراهقة على تعاطي المخدرات في المراهقة والثباب البالغ )، وبعد تحليل

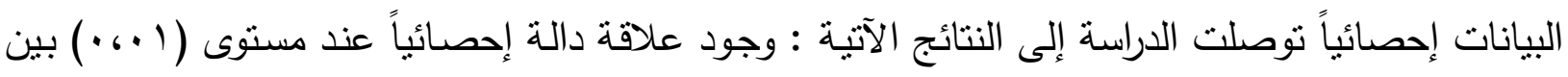

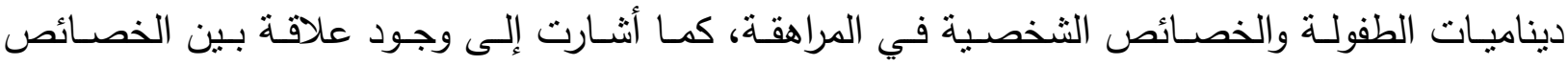

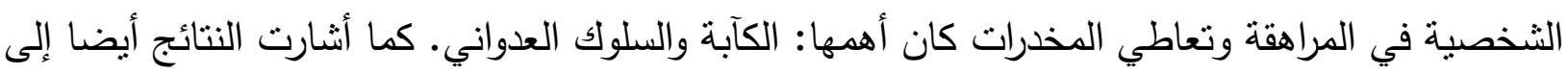

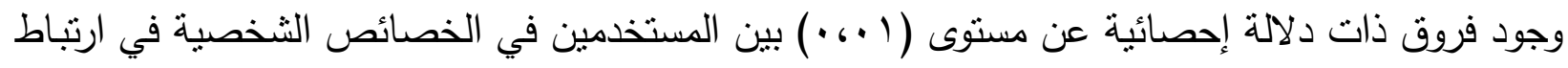
تعاطي المواد النفسية عن غير المتعاطين (424 - Brook et.al 1986,P.404).

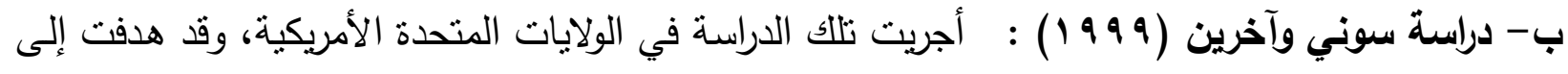

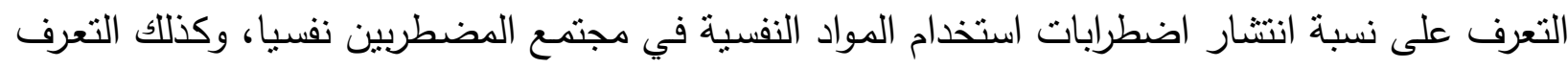

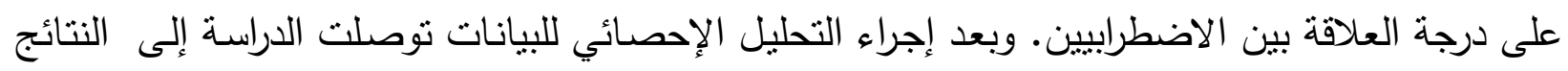

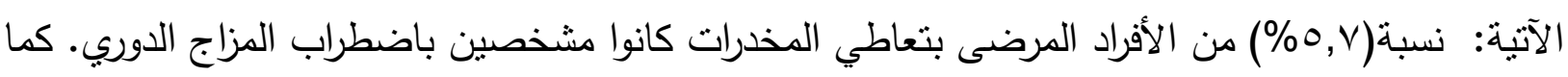

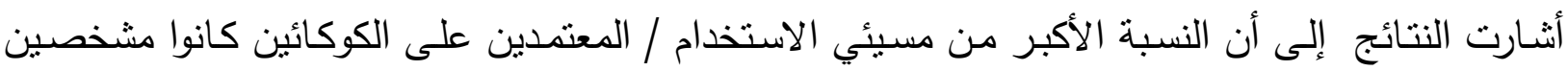

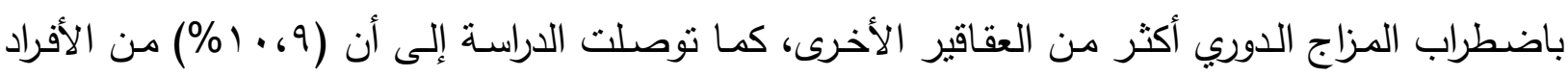

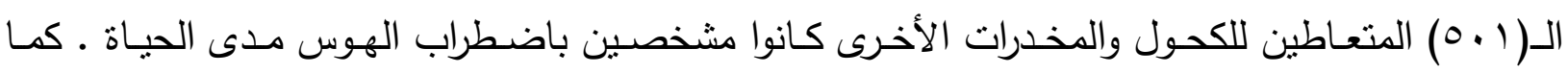

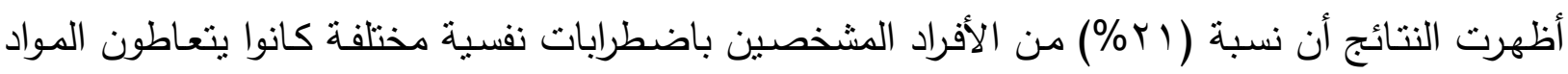

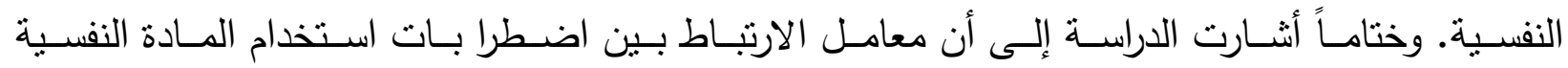
والاضطرابات النفسية ييلغ (ro\%). وذلك يؤشر علاقة عالية نسبيا بين النوعين من الاضطرابات - (Sonne et.al, 1999, P.609-627)

\section{1 - 1 مجتمع البحث وعينته :}

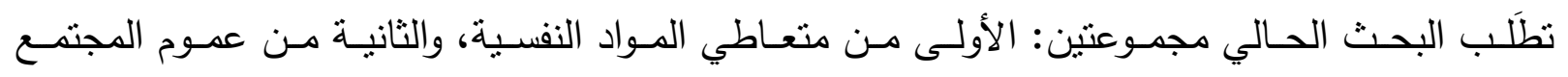

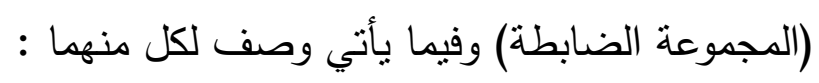

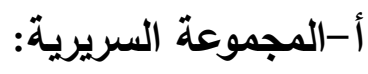

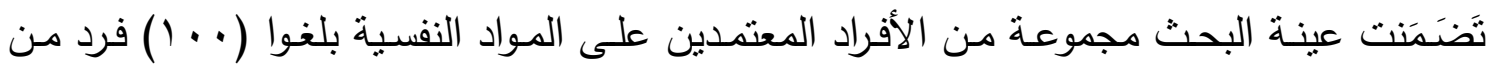

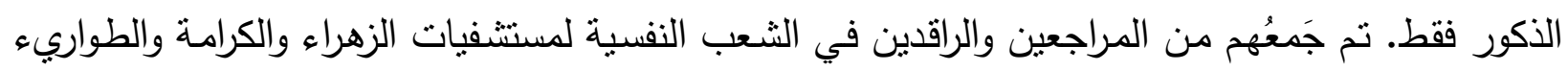


في الكوت ، إضافة إلى عيادتين خارجيتين لأطباء نفسانيين. وهي مجموعة قصدية بطبيعة الحال ،وكان يتم تطبيق أداة البحث باسلوب المقابلة الفردية.

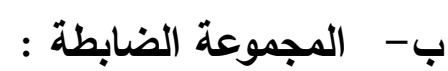

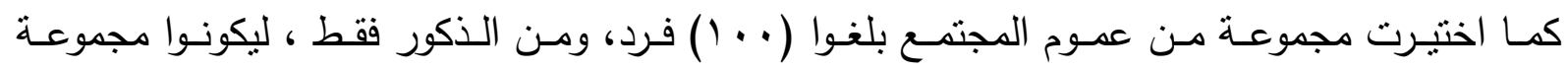

$$
\text { مقارنة(ضابطة). }
$$

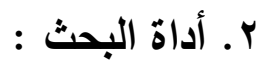

\section{أ - أ - جمع الفقرات وصياغتها:}

لبناء مقياس الضغط النفسي والاجتماعي للإدمان، تم صياغة عدد من الفقرات من بعض التعريفات

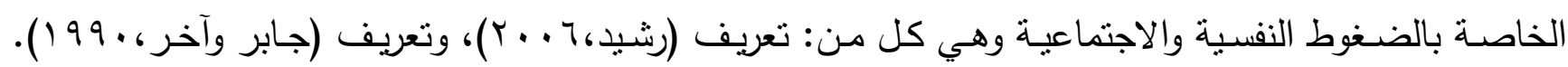

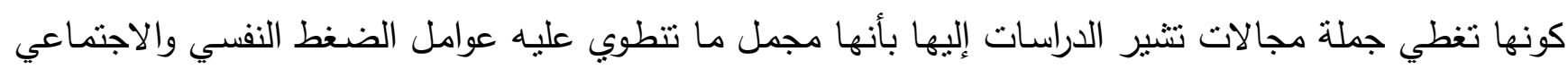

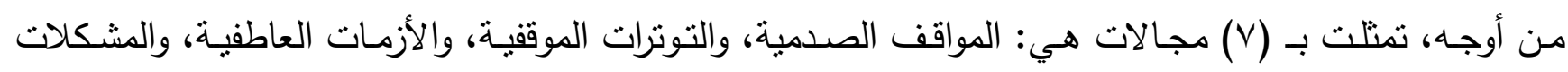

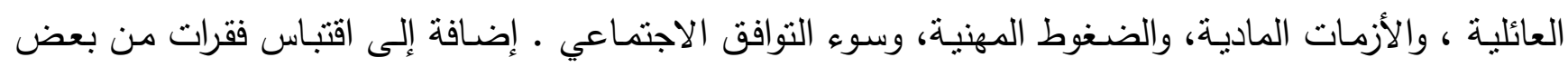

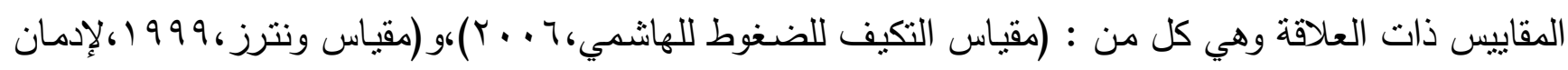

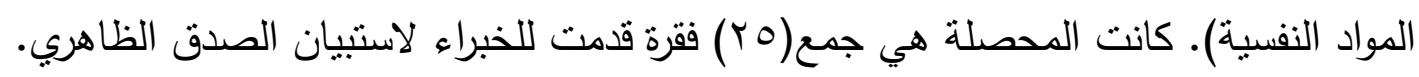

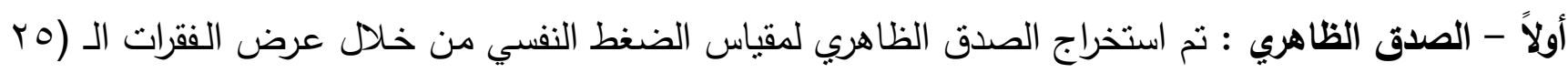

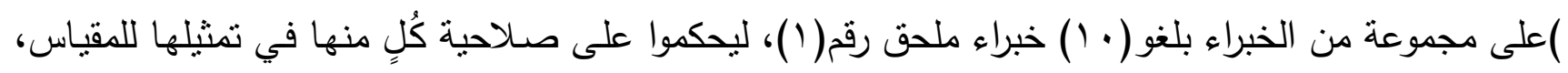

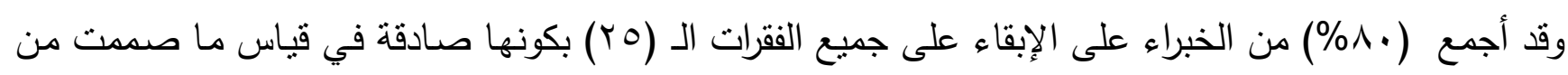
أجل قياسه ظاهرياً.

ثانياً - صدق البنـاء : يمكن الاستـلال على مؤشرات صدق البناء من خـلال ارتباط كل فقرة بالدرجـة الكليـة

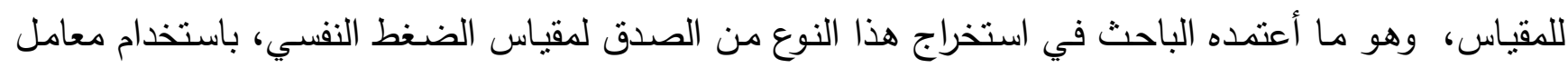

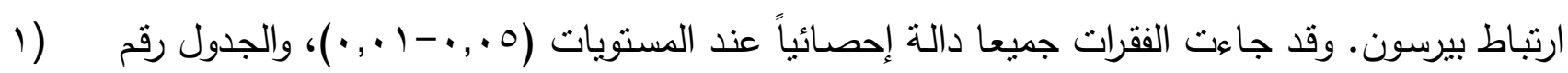

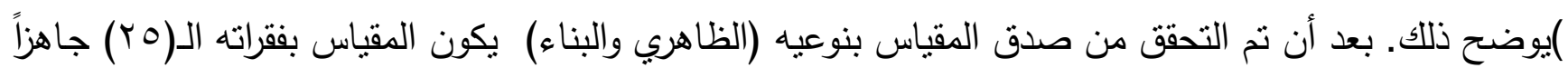

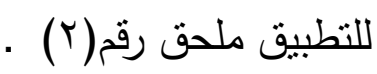

(1) الجدول رقم

\begin{tabular}{|c|c|c|c||}
\hline \\
\hline
\end{tabular}




\begin{tabular}{|c|c|c|c|}
\hline$\cdot, \wedge r$ & iv & $\cdot, \wedge \wedge$ & $r$ \\
\hline - ,qr & 11 & $\cdot, 9$. & $\varepsilon$ \\
\hline$\cdot, \wedge q$ & 19 & $\cdot, \wedge \varepsilon$ & 0 \\
\hline . & $r$. & $\cdot, \wedge q$ & 9 \\
\hline$\cdot, v$. & rl & $\cdot, \wedge q$ & $v$ \\
\hline$\cdot, \wedge$ & $r r$ & $\cdot, \mathrm{V} \vee$ & $\wedge$ \\
\hline \multirow[t]{6}{*}{$\cdot, \wedge r$} & $r r$ & .9 . & 9 \\
\hline & & .91 & 1. \\
\hline & & $\cdot, \wedge \vee$ & 11 \\
\hline & & .9 . & Ir \\
\hline & & $\cdot, v q$ & ir \\
\hline & & $\cdot, \wedge 1$ & $1 \varepsilon$ \\
\hline
\end{tabular}

ب -الثبات: استخرج الباحث الثبات بطريقة إعادة الاختبار، بعد فنرة أسبوعين من التطبيق الأول،وباستخدام

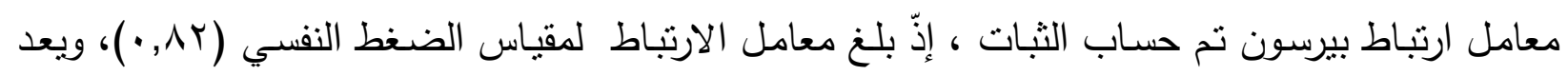
ذلك مؤشراً لثبات مقياس عالِ نسبياً .

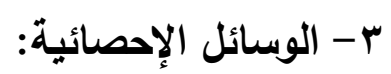
استعمل الباحث الوسائل الإحصائية الآتية لتحقيق مطالب بحثه وهي:

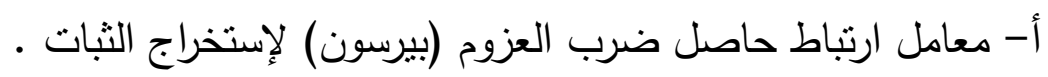
ب- الاختبار التائي لعينتين مستقلتين لمعرفة الفروق في الضغط النفسي .

\section{مرض النتائج ومناقشتها}

ولتحقيق هدف البحث المتمثل بـ معرفة (معرفة اثز عوامل الضغط النفسي والاجتماعي على سلوك

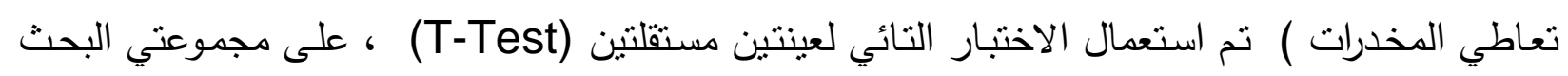

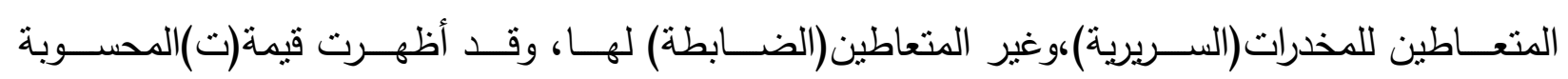

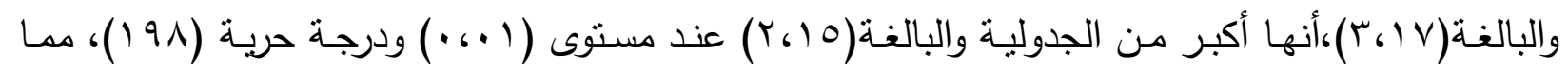

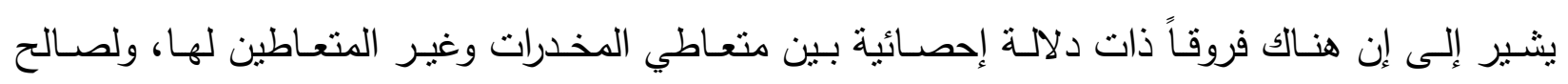

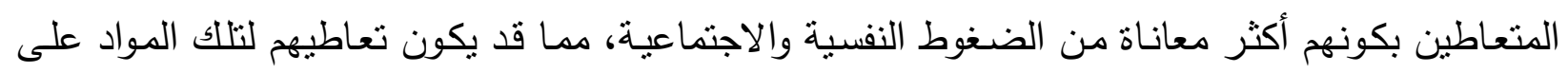

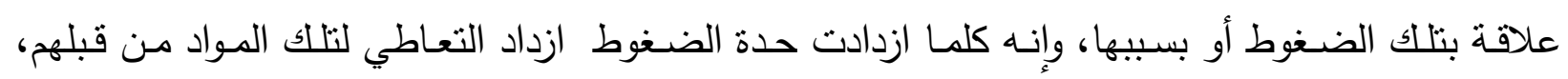
وبالعكس، والجدول رقم (Y) يبين ذلك . 


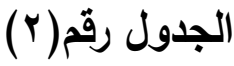

قيم (ت) لعينتين مستقلتين لمجموعتي المتعاطين للمخدرات وغير المتعاطين لها

\begin{tabular}{|c|c|c|c|c|c|c|c|}
\hline مستوى & قيمة ت & قيمة ت & لدرجة & \multicolumn{2}{|c|}{ الاتحراف المعياري } & \multicolumn{2}{|c|}{ المتوسط } \\
\hline \multirow[t]{2}{*}{$\cdot, \cdot 1$} & \multirow[t]{2}{*}{ r, ro } & \multirow[t]{2}{*}{$r, I V$} & \multirow[t]{2}{*}{191} & متعاطين & متعاطين & متعاطين & متعاطين \\
\hline & & & & \& & , , ro & r & VY \\
\hline
\end{tabular}

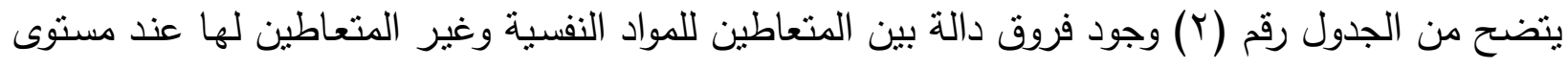

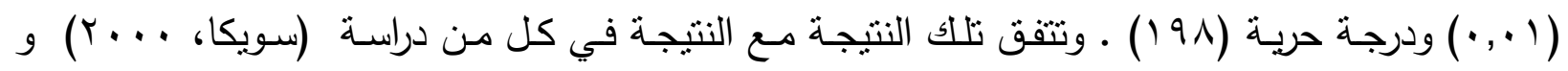

| الاستنتاجات

ا- إن متعـاطي المخدرات يختلفون عـن غير المتعـاطين في جملـة مـن المعـالم النفسية والسـلوكية

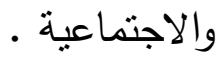

r- إن الأفراد المتعاطين هم أكثر تعرضاً للضغوط النفسية والاجتماعية من غير المتعاطين، ومن بين

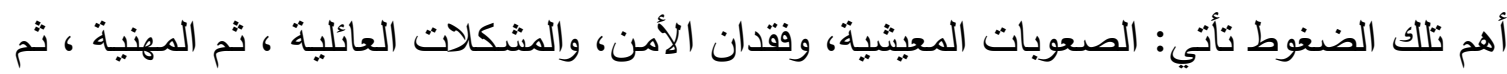
العلاقات الاجتماعية وبضمنها العاطفية .

r- إن المشكلة لا تقتصر على فئة عمرية أو اجتماعية واحدة ، ولكنها أكثر ما نتركز بأعمار المراهقة

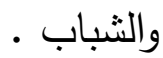

ــ إن الحاجة للأمن تؤلف ضغطاً موققياً استثنائيا في صورة الميدان النفسي العراقي الحالي المثخن بالمكلات والضغوط بمختلف درجاتها البسيطة والمنوسطة والحادة. 0ـ إن للتوترات والمشاعر النفسية الذاتية كالاكتئاب والقلق والإحساس بالقهر المرتبطة بضغوط خارجية

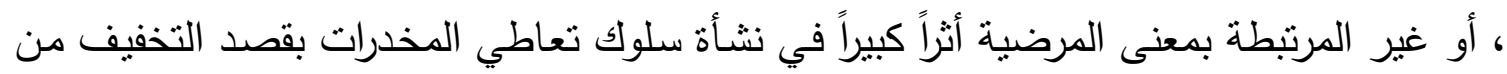

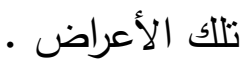

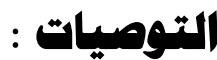

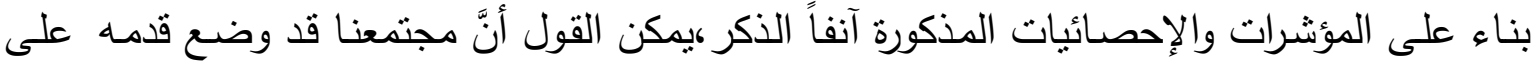

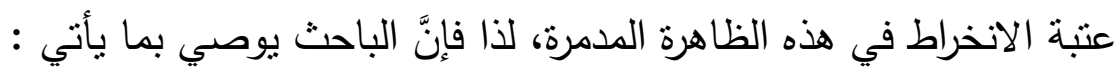
1- التصدي بقوة وسرعة من الجميع: مؤسسات حكومية ومنظمات اجتماعية وهيئات صحية وتربوية التهاتية ودينية، لهذا الآتون المدمر (إدمان المخدرات) قبل استفحاله، ذللك آن علاج المرض في بدايته

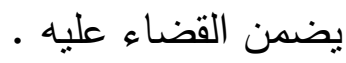


r- قيام وزارة الداخلية بتكثيف الجهود لمراقبة حدود العراق ، ووضع قوات متخصصة في المخافر الحدودية مهنها مراقبة نشاط تهريب المخدرات .

r- تكثيف وزارة الأمن الوطني الجهود والمتابعة للحصول على معلومات استخبارية عن أي نشاط

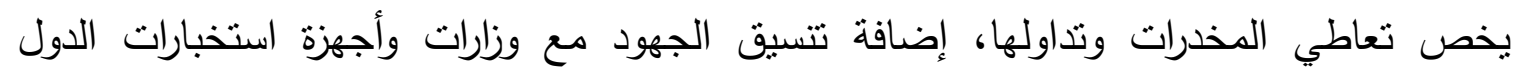

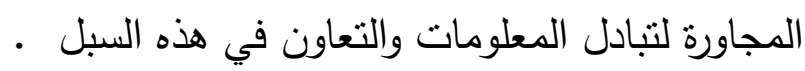

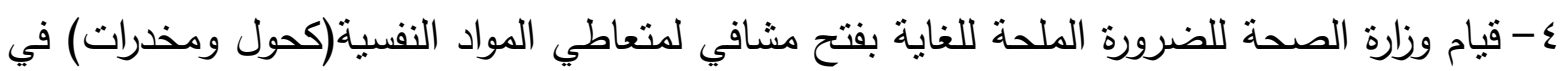

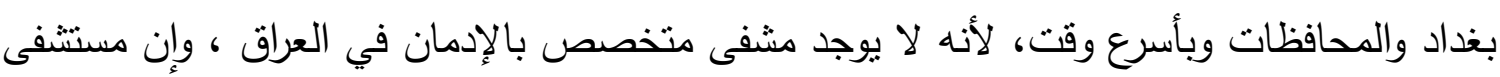

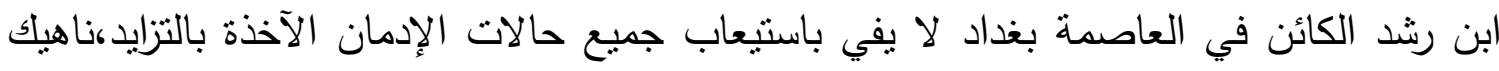

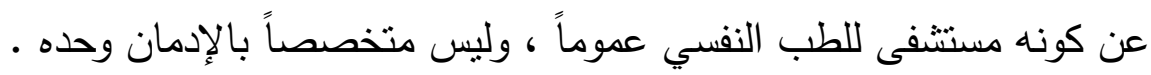
ه- تأليف وزارة التعليم العالي تأليف لجنة من المختصين في العلوم النفسية والاجتماعية والطب النفسي ولني

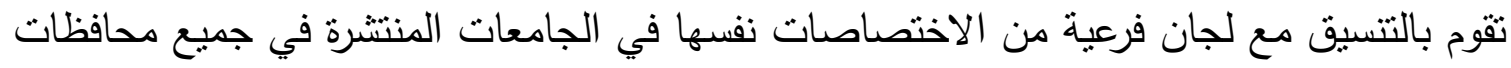
العراق، تتولى القيام بدراسات مسحية واسنطلاعات حول الظاهرة .

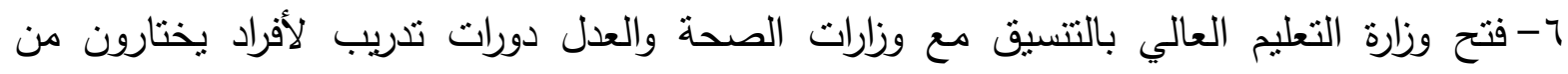

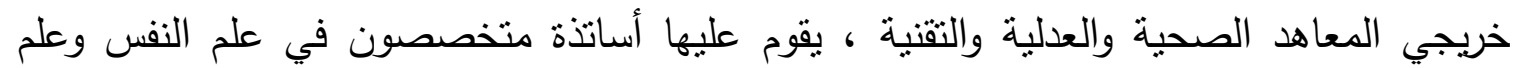

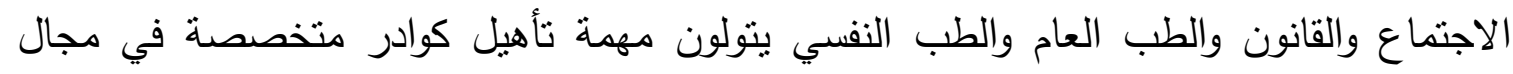
الإدمان على اعتبار صلة الظاهرة بتلك الجوانب . V- على وزارة التربية فتح دورات في مديريات التربية بالمحافظات للمرشدين التربويين ومدراء الددارس يحاضر فيها أساتذة متخصصون في العلوم النفسية والاجتماعية والطب النفسي والقانون، يتتاولون

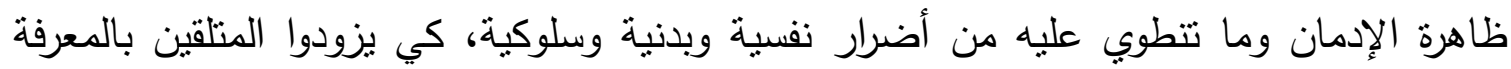

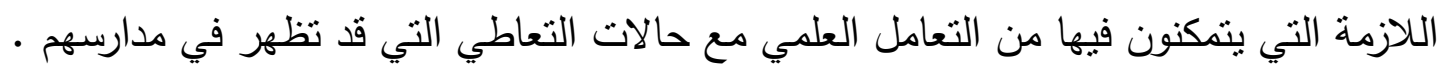

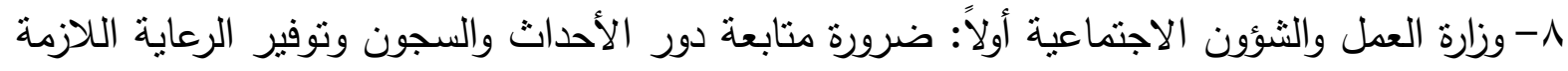

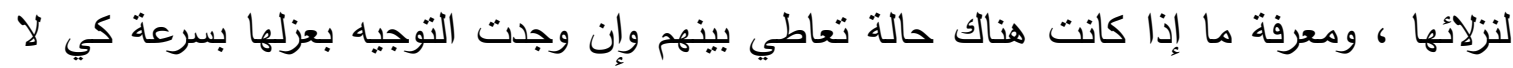

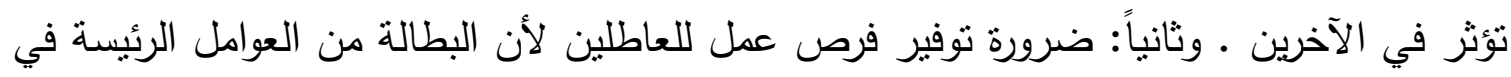

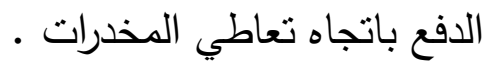
9- على وزارة الثقافة والإعلام ضرورة تتاول ظاهرة تعاطي الدخدرات في جميع وسائل الإعلام المقروءة

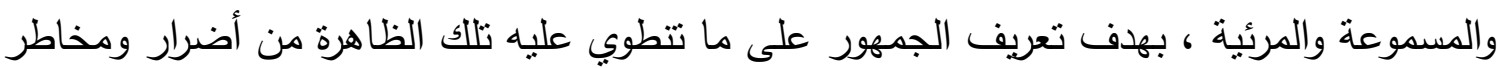

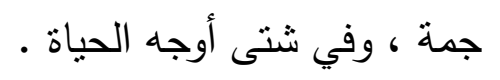

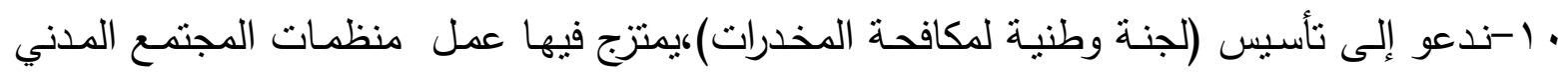

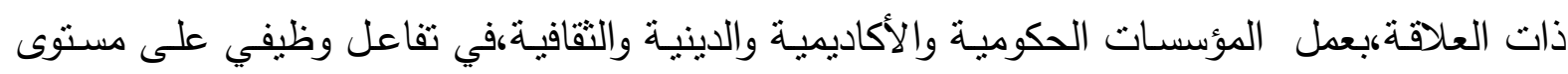

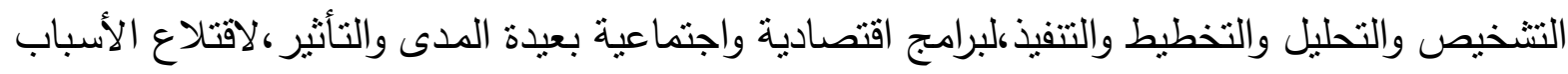

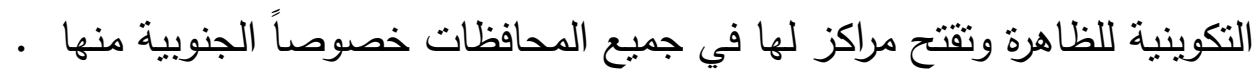


1- قيام دراسة مسحية وبائية لظاهرة تعاطي المخدرات توفر إحصائيات حول الظاهرة، كي نقف من

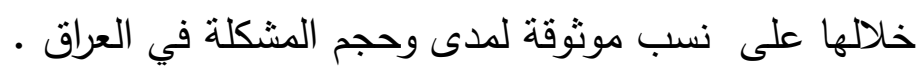

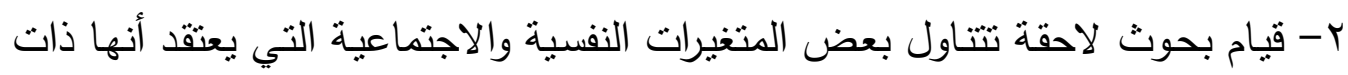

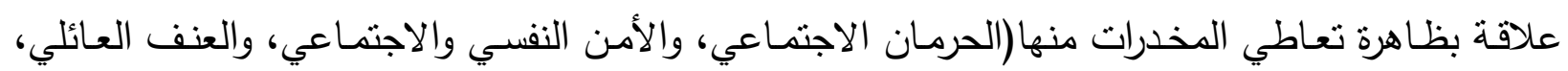

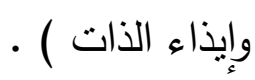
ب- كما يقترح الباحث تتاول بعض المتغيرات الديموغرافية بالدراسـة منها (اليتم، والمسنتوى المعانشي،

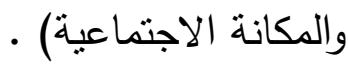

1. بعشر طه، كاتاتسكي ماريلين (919 (19) : العقاقير في العالم الإنلامي وسوء العقاقير في الأمريكينين. مجلة التربية والعلوم

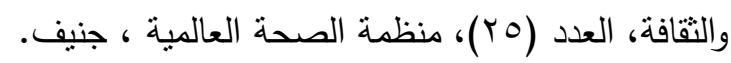
r. جابر ، جابر عبد الحميد وكفافي، علاء الدين (.99 19) : قاموس علم النفس والطب النفسي، الدجلد / آ، دار النهضة

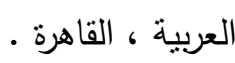

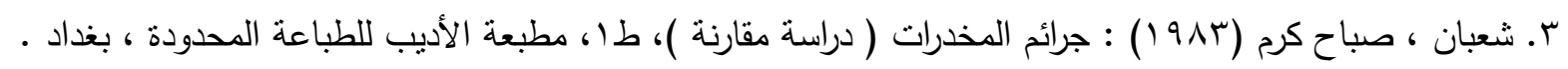

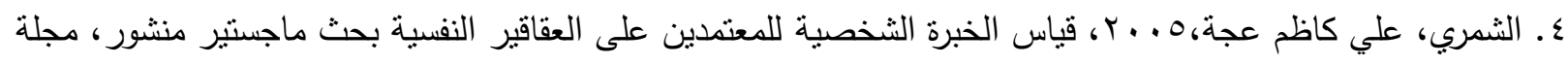

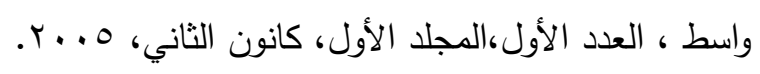

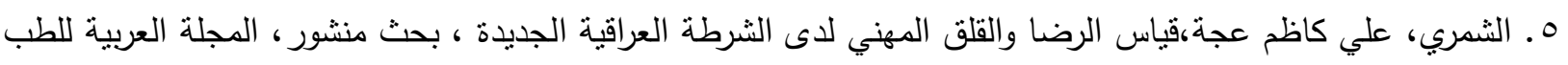

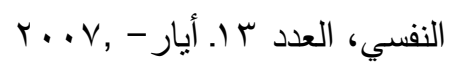

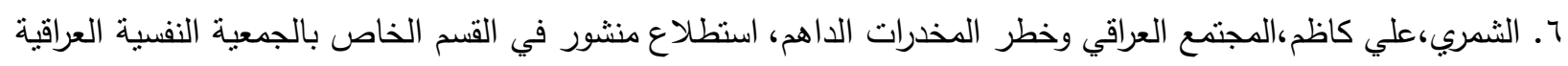

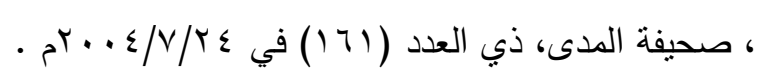

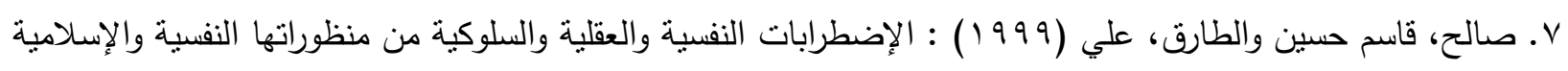

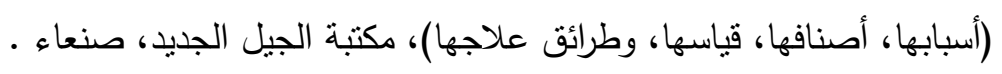

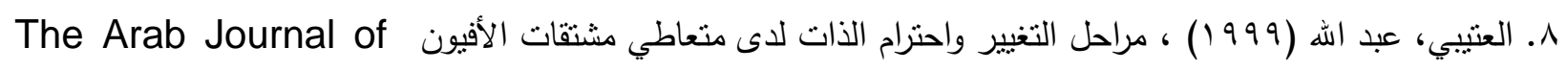

.Psychiatry, Vol. 10 , No. 2 .

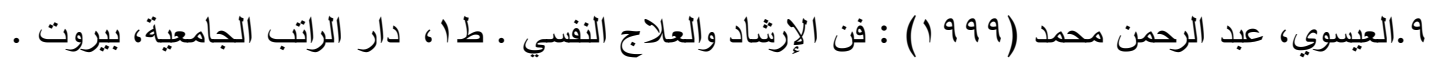

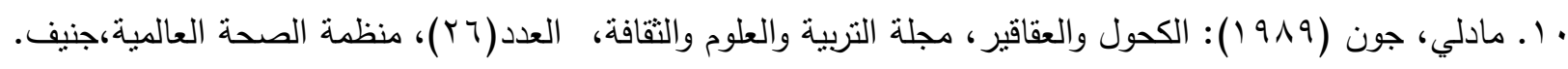

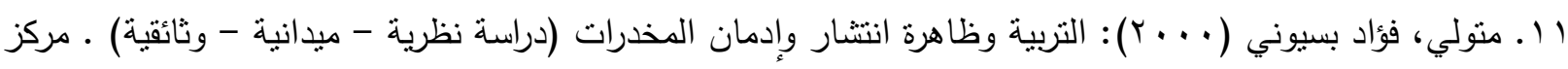

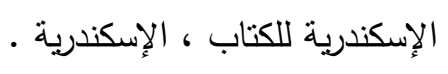

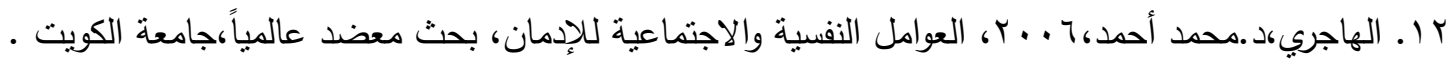

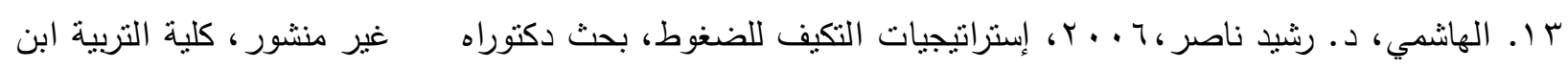
الهيثم،جامعة بغداد. ع ا. الهواري، محمد محمود (9AYV (19V) : المخدرات من القلق إلى الاستعباد ـ كتاب الأمة، قطر . 


$$
\begin{aligned}
& \text { 1 ـ الهويجي ، عبد الله سالم (؟99 1) : تأثير الأدوية على الجهاز العصبي المركزي ، دار الرواد ، طرابلس - ليبيا . }
\end{aligned}
$$

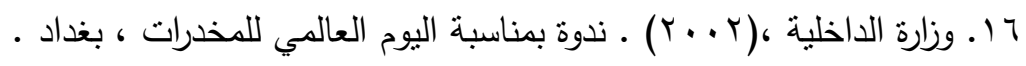

17. Brook, J. S.; Whiteman, M.; Gordon, A. \& Cohen, P. (1986) . Dynamics of childhood and adolescent personality traits and adolescent drug use, Developmental Psychology. Vol. 22, No. 3, American Psychiatric Association, Inc .

18. Buhringer, G.; Greenwood, J.; Gsellhefer, B.; Kunzel, J. \& Torrons, M. (2000). Drug use and HIV infection: The care of drug users and the treatment system, WHO, Regional office for Europe, scherfiqsviej 8, Copenhagen, Denmark .

19.DSM-IV-TR-TM(2000).Substance related disorder (4ed.), Text Revision. American Psychiatric Association, Washington, DC .

20.Kandel,D.B.(1978).Longitudinal Research on drug use: Empirical findings and methodological issues, John Wiley \& sons, New York .

21.Kaplan, H. \& Sadock, B. J. (1995). Comprehensive textbook of psychiatry VI, Vol. 1, (6th. ed), Williams \& Wilkins, Baltimore .

22. Leavitt, F. (1982). Drugs and behaviors, (2ed.) . John Wiley \& Sons .

23.Maremmani, I. (1999). Heroin addiction and related clinical problems, the official Journal of Europe, Vol. 1, No.2. Dicembre. European Opiate Addiction Treatment Association, Published by Italy .

24. National Institute on Alcohol Abuse and Alcoholism (NIAAA)(2000) . 10th speical report to congress : highlights from current research . Bethesda Maryland: Us department of health human services.

25. Oppenheimer, E. ; Sheehan , M. \& Taylor , C. (1988) . Letting the Client Speak: Drug Misuses and the process of help seeking . British Journal of addiction .

26. Penk, W. E. ; Woodward, W. A. ; Robinowitz, R. \& Hess , J. L. (1978) . Differences in MMPI scores of Black and white compulsive heroin users. Journal of Abnormal Psychology, Vol. 87, No.5 .

27. Sonne , S. C. \& Brady, T. K. (1999) . Substance Abuse and bipolar co morbidity, The Psychiatric Clinics North America, Vol. 22 , No. 3 , September .

28. Soyka , M. (2000). Substance misuse, psychiatric disorder and violent and disturbed behavior , British Journal of Psychiatry Vol. 11,No.7 .

29. UNDCP Publications (1997). Facing in challenge, Vienna, No.21

30. UNDCP Report (2006). The epidemiology of the drugs, Geneva .

31. UN publications (2006) . For the free world of the drugs, Printed in Austria .

32. UN Publications, UNESCO , (1996) . By victor kolybine \& Davis Battenberg, Cultures and Drugs , Indentation Texts .

33. WHO report (2000) . Principle preventing HIV Infection among drug users WHO regional office for Europe .

34. Winters , K. C. (1999) . Anew multi scale measure of adults substance abuse. Journal of Substance Abuse Treatment, Vol. 16, No. 3, Elsevier Science Inc., U. S. A.

35.WHO,(1992).International Classification of disease (10th Rev) . Geneva : World Health Organization . 


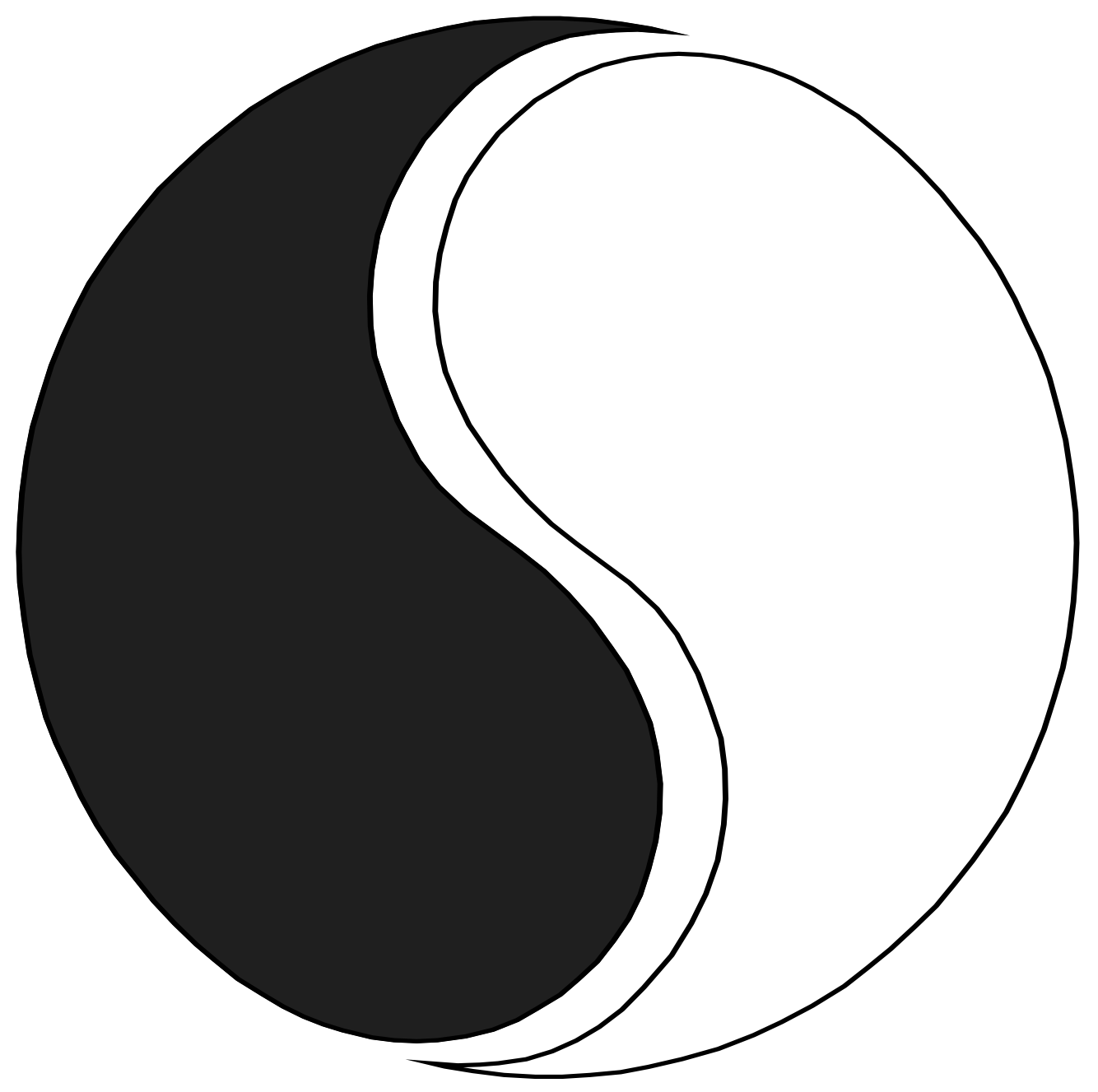

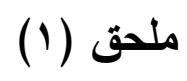

أسماء الساد ة الخبراء على صلاحية فقرات مقياس الضغط النفسي والاجتماعي 


\begin{tabular}{|c|c|c|c|}
\hline موقع العمل & الارجة العلمية & الاسم الكامل & $ت$ \\
\hline قسم علم النفس/ آداب / جامعة بغداد & 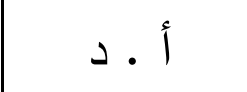 & خليل إبراهيم رسول & 1 \\
\hline قسم علم النفس/ آداب / جامعة بغداد & أ ـ ـد & وهيب مجيد الكبيسي & r \\
\hline قسم علم النفس/ آداب / جامعة بغداد & أ ـ ـد & قاسم حسين صالح & r \\
\hline قسم العلوم التربوية والنفسية/ كلية التربية & أ أ ـد & كامل الكبيسي & $\varepsilon$ \\
\hline قسم العلوم التربوية والنفسية/ كلية التربية & أ أ ـد & صباح العجيلي & 0 \\
\hline قسم علم النفس / اداب / جامعة بغداد & أ .م •.د & بثينة منصور الحلو & 1 \\
\hline قسم العلوم التربوية والنفسية/ كليةالتربية/ & م م د & مهند عبد الستار العبيدي & $V$ \\
\hline قسم علم النفس/ آداب / جامعة بغداد & أ. م. م. د & احمد لطيف الدليمي & $\wedge$ \\
\hline قسم علم النفس/ آداب / جامعة بغداد & م • مد & خلدون العبيدي & 9 \\
\hline قسم علم النفس / اداب / جامعة بغداد & 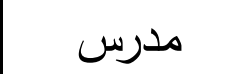 & فارس كمال عمر نظمي & 1. \\
\hline
\end{tabular}

ملحق (r)

مقياس الضغط النفسي والاجتماعي 
فيما يأتي عدد من الفقرات التي تستفسر عن معدل حدوث بعض المشكلات لديك ، وموافقتلك أو

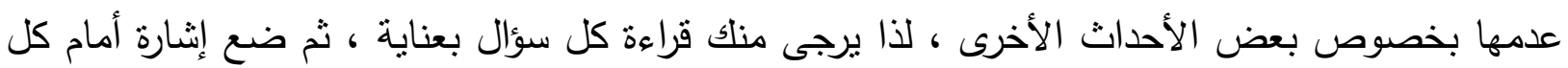

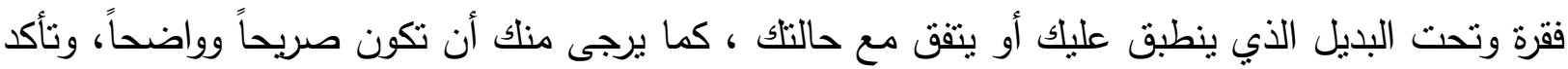

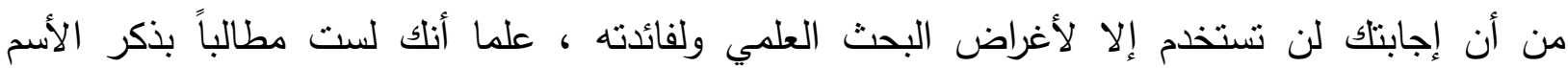
... مع التقدير .

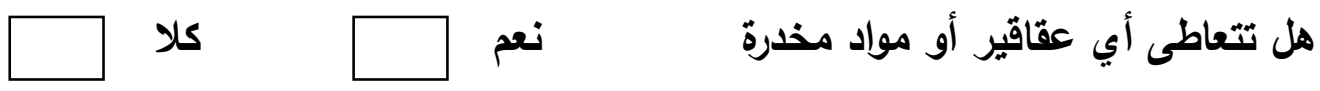




\begin{tabular}{|c|c|c|c|c|c|}
\hline تقريبا" & 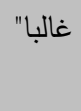 & 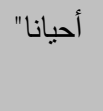 & مرة & 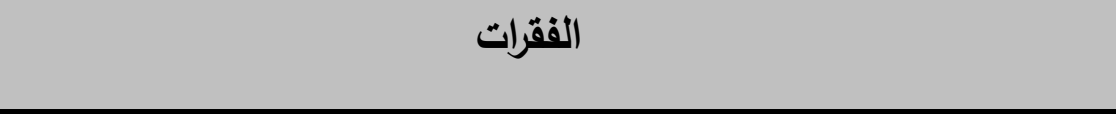 & $ت$ \\
\hline & & & & ما تعرضت له من صدمات وفقدان يشعرني بالخسارة . & 1 \\
\hline & & & & لدي مشكلات في البيت تجعلني منوتراً وضجراً . & r \\
\hline & & & & أثنعر بإني لم أحقق شيئا مما أردت والظروف المحيطة بي تزيد إحباطي . & r \\
\hline & & & & ذهني مشغول بالمشكلات والضغوط الني تواجهني . & $\varepsilon$ \\
\hline & & & & تمر بي أوقات أكون فيها متهيجا" أو منزعجا" بسبب الوضع المتدهور في الثنارع . & $\circ$ \\
\hline & & & & أعاني مشكلة في الدراسة . & 1 \\
\hline & & & & أنشعر إنهُ لبس هناك من يفهني . & $\checkmark$ \\
\hline & & & & لدي مشكلة مع من أحب . ل & $\wedge$ \\
\hline & & & & أشعر بالخوف من أن أذهب ضحية العنف السائد في الثارع . & 9 \\
\hline & & & & أعاني من ضغوط في العمل . & 1. \\
\hline & & & & أعتق إن أساس كل مشاكلي هو عوزي للمال . & 11 \\
\hline & & & & أستدين المال كي أَفيّ بمنطلباتي ومنطلبات عائلتي . & ir \\
\hline & & & & أنشعر إنَّ ما من شيء أقوم به وينجح · & ir \\
\hline & & & & يقلقني أن يمرض أحد أفراد عائلتي لعدم قدرتي على معالجته بسبب ضعف حالتي المادية . & $1 \varepsilon$ \\
\hline & & & & أشعر بالقلق نتيجة ظروف مهنتي الخطرة . & 10 \\
\hline & & & & أثنعر بالضيق نتيجة للضغوط المستمرة المتكررة . & 17 \\
\hline & & & & أعاني من أرق بسبب انشغال ذهني بالمشكلات . & iv \\
\hline & & & & أرى إنه لبس هناك أمل في أن يتحسن الوضع . & 11 \\
\hline & & & & تعرضت للخذلان من أصدقائي وأقاربي . & 19 \\
\hline & & & & أثنعر بضعف قدرتي على تحمل ما أواجه من ضغوط . & r. \\
\hline & & & & أعاني من انزعاج عندما تطلب مني عائلتي شيئاً لا أسنطيع توفيره لهم & r \\
\hline & & & & كلما قلت في نفسي لماذا هكذا يحصل لنا ولا نعيش منل باقي البلدان شعرت بالمرارة . & rr \\
\hline & & & & قلقي الدائم من أن أفقد أحد أعزائي بسبب العنف السائد في الثشارع . & $r+$ \\
\hline & & & & تراودني أحلام في النوم وفي اليقظة تعكس ما أواجه من مشكلات وضغوط في الواقع . & $r \leq$ \\
\hline
\end{tabular}

